\title{
Response of Some Soybean Germplasm to Mangan Toxicity
}

\author{
Heru Kuswantoro ${ }^{1}$ \\ ${ }^{1}$ Indonesian Legume and Tuber Crops Research Institute, Indonesian Agency for Agricultural Research and \\ Development, Malang, Indonesia \\ Correspondence: Heru Kuswantoro, Indonesian Legume and Tuber Crops Research Institute, Indonesian Agency \\ for Agricultural Research and Development, Malang, Indonesia. E-mail: herukusw@yahoo.com
}

Received: February 3, 2015 Accepted: April 1, $2015 \quad$ Online Published: April 3, 2015

doi:10.5539/ijb.v7n3p1 URL: http://dx.doi.org/10.5539/ijb.v7n3p1

\begin{abstract}
In excessive manner, mangan $(\mathrm{Mn})$ as an essential nutrient can be toxic to the plant. This phenomenon often occurs in acid soil. Hence, it is needed gene resources to develop plant in acid soil. The soybean germplasm tolerance to Mn toxicity was tested in seed laboratory, using two factors experimental design. The first factor was Mn toxicity containing two treatments (1) $0 \mathrm{ppm} \mathrm{Mn} \mathrm{in} \mathrm{pH} 7$ as control, and (2) solution concentration of $75 \mathrm{ppm} \mathrm{Mn}$ in $\mathrm{pH} 4$. The second factor was 14 accessions of soybean germplasm. Results showed that generally root characters decreases while shoot characters increased in Mn toxicity condition. However, some genotypes showed different performance. There was one genotype having the highest root dry weight in Mn toxicity condition, i.e. MLGG 0091 The highest root dry weight in this genotype was also supported by the root length and number of roots. MLGG 0091 was also capable to increase the length epicotyle that contribute to the increase in seedling dry weight. Therefore MLGG 0091 can be used as a gene source for tolerance to Mn toxicity.
\end{abstract}

Keywords: tolerance of acidity and Mn, characterization, germplasm, soybean

\section{Introduction}

Mangan is an essential nutrient that can be toxic to the plant in excessive manner (Marschner, 1995). Mn level in a soil is controlled by Mn availability in soil, $\mathrm{pH}$ and electron availability (Adams, 1981; Sparow and Uren, 1987). Soil with high $\mathrm{Mn}$ availability can cause Mn toxicity in soil pH below 6.0 (Hue et al., 1987). In high electron environment, caused by excessive watering, low drainage, or high organic manure application, Mn toxicity is able to arise even in alkaline $\mathrm{pH}$ (Hue, 1988). It is because some organic molecules are capable to split Mn oxide through electron transfer in reductive process (Stone \& Morgan, 1984).

Mn toxicity in acid soil is a complex trait and involving multiple physiological and biochemical mechanisms (Millaleo et al., 2010). Beside, at different times during the growing and in the same soil season, manganese can be deficient and toxic to plants (Johansen, 2005). One of the reasons is Mn toxicity relates to other nutrients availability. Mn toxicity also decreases due to high availability of other nutrients in the soil such as Ca (Horst, 1988), Mg (Goss et al., 1991), and Si (Horst \& Maschner, 1978).

Plant species differences or even variety differences in a species have different response level to Mn toxicity (Foy et al., 1988; Reddy et al., 1991). Mn toxicity in Phaseolus vulgaris is identified at $0.5 \mathrm{uM}$ if the nutrients solution free of $\mathrm{Si}$ (Horst \& Marschner, 1978). In soybean, Mn toxicity is identified at $15 \mathrm{ppm}$ (Heenan \& Carter, 1976). In this research, response of some germplasm to Mn toxicity was studied.

\section{Materials and Method}

Response of some soybean germplasm to mangan toxicity was conducted in Seed Laboratory of Indonesian Legume and Tuber Crops Research Institute, Malang-Indonesia. Research was carried out by using factorial design of randomized complete block design (RCBD). The first factor was Mn toxicity containing two treatments (1) $0 \mathrm{ppm} \mathrm{Mn} \mathrm{in} \mathrm{pH} 7$ as control, and (2) solution concentration of $75 \mathrm{ppm} \mathrm{Mn}$ in $\mathrm{pH} 4$. The second factor was 14 accessions of soybean germplasm.

A total of 25 sterilized soybean seeds were germinated in a petridish. A gauze was put inside the petridish to ensure the germinated seeds to be able to stand straight up. Solution was pour in the petridish up to half of seed size to maintain seeds respiration. The decreasing solution due to the absorption by the seeds was overcome by adding aquadest up to the specified limit. Germination was conducted at $25^{\circ} \mathrm{C}$. The observation was recorded on 
root length, root dry weight, hypocotile length, number of lateral roots, seedling dry weight and epicotyle length at 6 days after germinating.

\section{Results and Discussion}

The results showed that genotype MLGG 0147 and MLGG 0025 had the longest root length among the 14 tested genotypes, where the roots length of those two genotypes were more than $10 \mathrm{~cm}$. In Mn toxicity condition, the two genotypes also had relatively long roots. Other genotype having relatively long roots was MLGG 0091, with narrow standard deviation. There were two genotypes with root length longer or equal to the previous three genotypes, but the standard deviation were wider, i.e. MLGG 0096 and MLGG 0118 (Figure 1). High Mn concentration affected the roots becoming shorter (Abou et al., 2002), but the five genotypes were capable to maintain roots length than other ten genotypes.

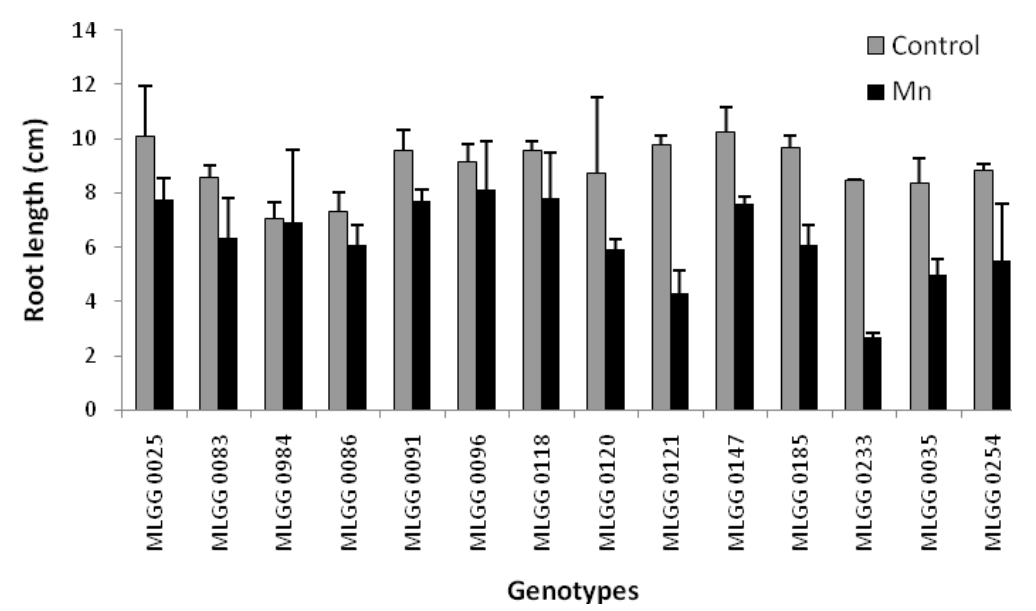

Figure 1. Root length of soybean germplasm in control and Mn toxicity conditions

Genotype MLGG 0233 was the genotype with shortest root length in Mn toxicity condition. However, in condition without Mn toxicity (control), this genotype was able to grow its roots up to $8 \mathrm{~cm}$ long. Other genotypes having the shortest root length in Mn toxicity condition was MLGG 0121. In normal conditions, this genotype was remain able to perform roots length almost $10 \mathrm{~cm}$. Therefore, based on root length these two genotypes were classified as Mn toxicity sensitive genotypes (Figure 1). The highest percentage decrease in root length was shown by MLGG 0233 and MLGG 0121, i.e. $68.65 \%$ and $55.71 \%$ respectively. Genotype with the lowest of percentage of root length decrease was MLGG 0984, where the percentage of root length decrease was $3.45 \%$ (Table 1). Root resistance to Mn toxicity was the environmentally sensitive quantitative traits (Kaseem et al., 2004), that affected by the environments.

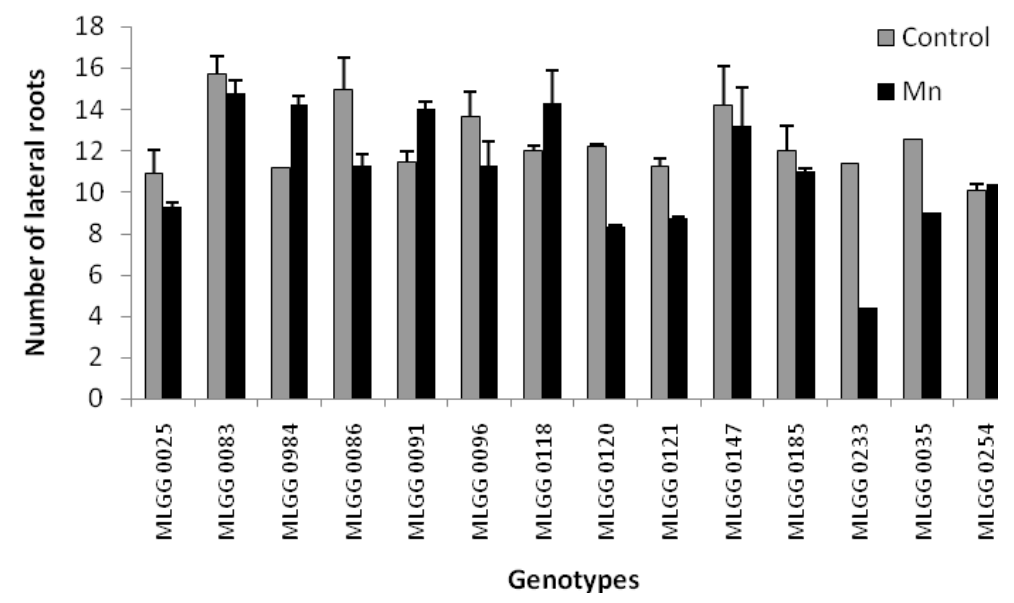

Figure 2. Number of lateral roots of soybean germplasm in control and Mn toxicity conditions 
Genotypes with the highest number of lateral roots was MLGG 0083 and MLGG 0086 in the control condition, while the least number of lateral roots was shown by MLGG 0233. In Mn stress conditions, MLGG 0083 also showed the highest amount of the root followed by MLGG 0984, MLGG 0091 and MLGG 0118 (Figure 2). Similar to the root length, number of lateral roots decreased in Mn toxicity condition. The highest decrease of the root number was shown by MLGG 0233 . Other genotypes showed a decrease in relatively high number of lateral roots were MLGG 0035, MLGG 0120 and MLGG 0086. Even though MLGG 0086 having a relatively high reduction in number of roots, but in stress condition the number of lateral roots was still relatively high. The interesting thing about this study is that there were several genotypes which have more number of lateral roots in stress conditions, three of them were MLGG 0984, MLGG 0091 and MLGG 0118 where the number of lateral roots increased $27.59 \%, 28.90 \%$ and $15.33 \%$ respectively (Table 1 ).

The highest root dry weight was shown by MLGG 0091 in Mn toxicity followed by MLGG 0035 also in Mn toxicity condition. It mean, root dry weight of some genotypes increased in Mn toxicity condition (Figure 3). Genotype having the lowest root dry weight was MLGG 0233, occurred in both of control and Mn toxicity conditions. For this genotype, it seemed that root dry weight was more affected by genetic factor than environmental factor, because root dry weight in different solution conditions were not significantly different. Other genotype having equivalent root dry weight in both two conditions was MLGG 0120. However, generally root dry weight decreased. The highest root dry weight decreasing were shown by MLGG 0025 and MLGG 0086, i.e. $23.69 \%$ and $23.38 \%$ (Table 1). Izaguirre-Mayoral and Sinclair (2005) also reported the decreasing of root dry weight when soybean grown in Mn solution from 60uM/L. Khabaz-Saberi et al., (2009) also reported that the increasing solution Mn concentration decreased root dry weight. Increasing root dry weight of Heliantus anuus in lower Mn concentration and then decreasing in higher concentration was reported by Hadjiboland et al. (2008). Soybean tolerance to Mn toxicity related with roots necrotic marker (Kaseem et al., 2004). It indicated the dammage of the roots caused by Mn toxicity. The increasing of root dry weight presumably was caused by the increasing root diameter such as root dry weight of cultivar IAC-15 increased by 63 and $116 \%$ with the increase of Mn (Junior et al., 2009).

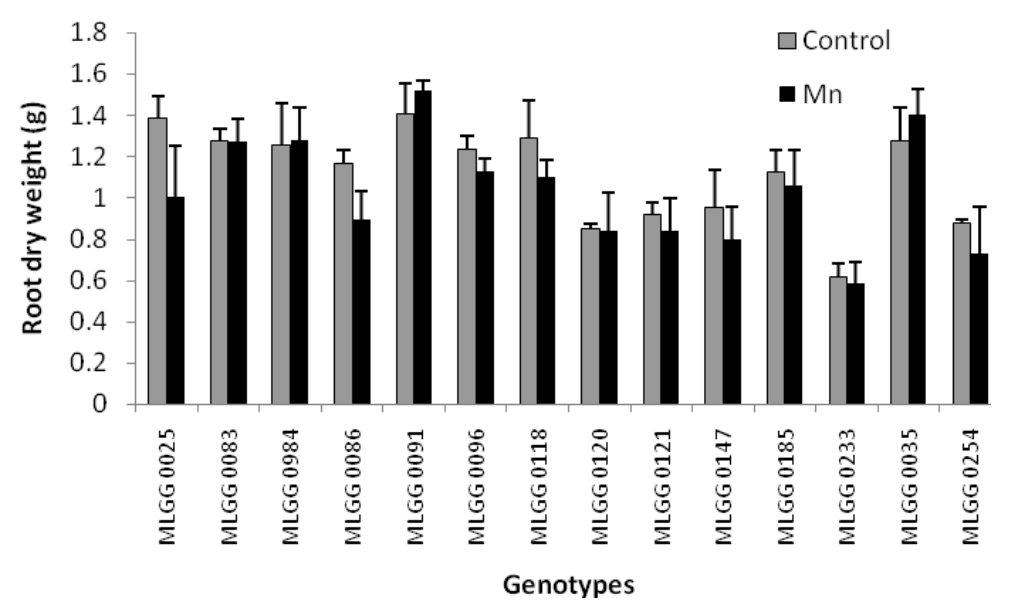

Figure 3. Root dry weight of soybean germplasm in control and Mn toxicity conditions

Hipocotyle length in control condition was higher than in Mn toxicity condition. In control condition, the highest hipocotyle length was achieved by MLGG 0121, followed by MLGG 0233, MLGG 0185 and MLGG 0086 (Figure 4). The decreasing hipocotyle length was achieved by MLGG 0233, while the lowest was achieved by MLGG 0096. However, there were some genotypes which had hipocotyle length higher in Mn toxicity condition than in control, i.e. MLGG 0086, MLGG 0984, MLGG 0083 and MLGG 0096. Therefore, the hipocotyle length increased in those four genotypes, with the highest increasing was achieved by MLGG 0984 as $17.17 \%$ (Tabel 2). In shortening of shoot, the high Mn concentration was also involved (Abou et al., 2002). 


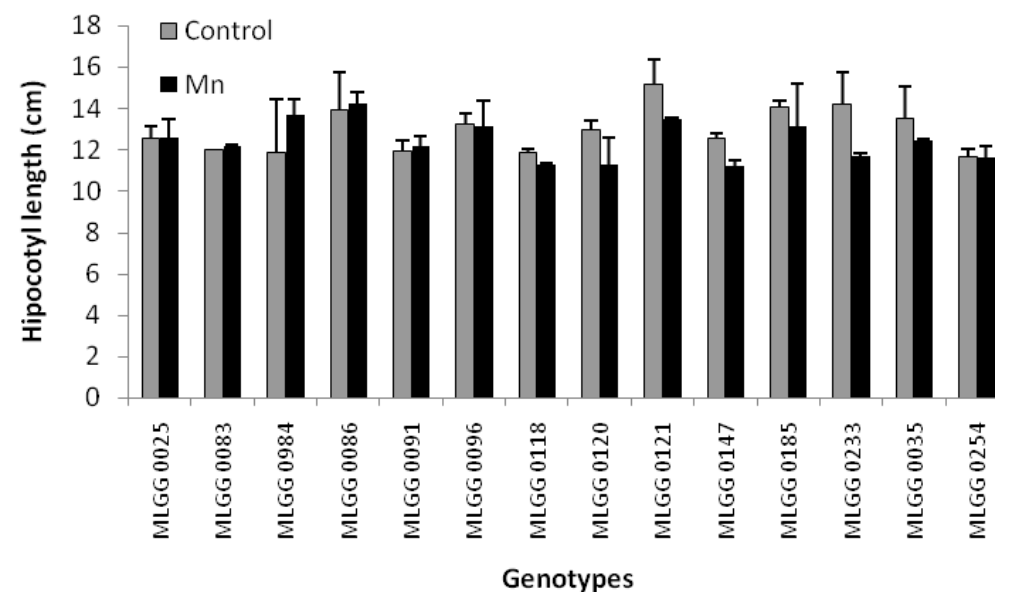

Figure 4. Hipocotyle length of soybean germplasm in control and Mn toxicity conditions

Unlike root length and hipocotyle length, epicotyle length in Mn toxicity condition was higher than in control condition. The highest epicotyle length was achieved by MLGG 0096 in Mn toxicity condition, followed by MLGG 0096 in control condition. Genetic factor also more affected in this genotype than environmental factor, because the difference of epicotyle length between Mn toxicity and control conditions was relatively low. It was different to the genotypes of MLGG 0035 and MLGG 0254, where in these two genoytpes epicotyle length in Mn toxicity condition was relativlely higher than in control condition (Figure 5). In these two genoytpes increasing epicotyle length achieved up to $163.89 \%$ and $113.16 \%$ respectively (Table 2 ).

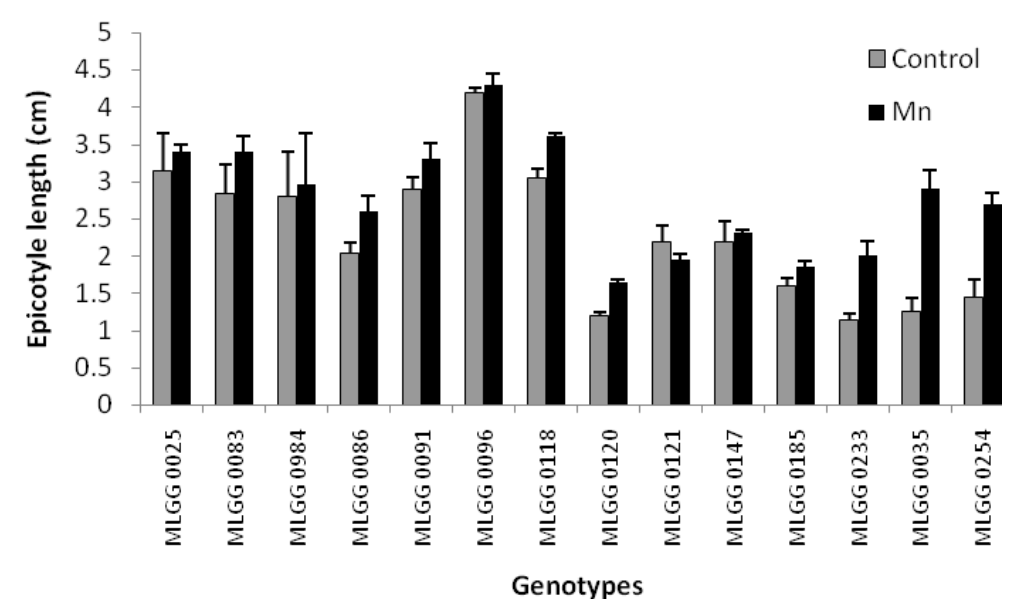

Figure 5. Epicotyle length of soybean germplasm in control and Mn toxicity conditions

The highest seedling dry weight was shown by MLGG 0091 in Mn toxicity condition, while the lowest was shown by MLGG 0233 in both Mn toxicity and control conditions (Figure 6). Generally, seedling dry weight decreases in Mn toxicity condition. The highest decreasing was shown by MLGG 0025 that achieved 21.87\%, while other genotypes had relatively low decreasing percentage. Some researcher also reported similar results, where increasing solution Mn concentration decreased shoot dry weight (Izaguirre-Mayoral \& Sinclair, 2005; Khabaz-Saberi et al., 2009). Some genotypes did not experience seedling dry weigth decreasing. Even, there were three genotypes that experienced seedling dry weight increasing in Mn toxicity conditions, i.e. MLGG 0091 and MLGG 0035 up to $7.32 \%$ and $8.14 \%$ respectively (Table 2). Reis and Junior (2011) reported the differences among the genotypes in leaves ultrastructural parts. Presumably, it also affected in whole seedling dry weight in addition to the difference due to seedling dry weight. 


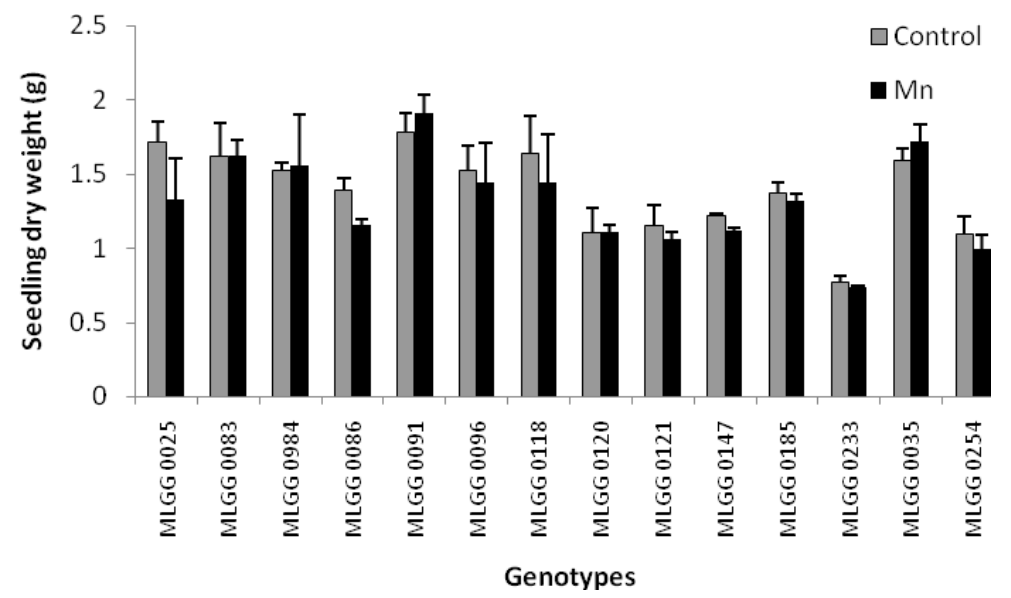

Figure 6. Seedling dry weight of soybean germplasm in control and Mn toxicity conditions

Table 1. Decrease percentage of roots length, number of roots, and root dry weight of soybean germplasm in Mn toxicity condition

\begin{tabular}{lccc}
\hline Genotypes & Root length $(\mathrm{cm})$ & Number of lateral roots & Root dry weight $(\mathrm{g})$ \\
\hline MLGG 0025 & 22.69 & 10.04 & 28.69 \\
MLGG 0083 & 26.11 & -0.52 & 0.88 \\
MLGG 0984 & 3.45 & -27.59 & -4.04 \\
MLGG 0086 & 16.52 & 15.35 & 23.38 \\
MLGG 0091 & 19.28 & -28.90 & -7.81 \\
MLGG 0096 & 11.39 & 6.28 & 8.67 \\
MLGG 0118 & 18.60 & -15.33 & 14.33 \\
MLGG 0120 & 27.56 & 30.90 & 1.46 \\
MLGG 0121 & 55.71 & 19.73 & 9.61 \\
MLGG 0147 & 25.43 & -11.46 & 16.91 \\
MLGG 0185 & 36.52 & -2.75 & 6.55 \\
MLGG 0233 & 68.65 & 61.48 & 5.26 \\
MLGG 0035 & 40.13 & 28.48 & -10.06 \\
MLGG 0254 & 38.12 & -5.97 & 17.82 \\
\hline
\end{tabular}

Table 2. Decrease percentage of hipocotyle length, epicotyle length, and seedling dry weight of soybean germplasm in Mn toxicity condition

\begin{tabular}{cccc}
\hline Genotypes & Hipocotyle length $(\mathrm{cm})$ & Epicotyle length $(\mathrm{cm})$ & Seedling dry weight $(\mathrm{g})$ \\
\hline MLGG 0025 & 0.05 & -20.84 & 21.87 \\
MLGG 0083 & -1.25 & -32.14 & -0.84 \\
MLGG 0984 & -17.17 & 5.68 & -1.65 \\
MLGG 0086 & -2.36 & -31.16 & 17.21 \\
MLGG 0091 & -1.85 & -16.47 & -7.32 \\
MLGG 0096 & 0.88 & -2.61 & 5.98 \\
MLGG 0118 & 5.45 & -18.56 & 10.98 \\
MLGG 0120 & 12.87 & -38.81 & -1.84 \\
MLGG 0121 & 10.96 & 9.62 & 7.78 \\
MLGG 0147 & 10.76 & -11.33 & 8.98 \\
MLGG 0185 & 6.56 & -18.65 & 4.18 \\
MLGG 0233 & 17.39 & -72.31 & 5.04 \\
MLGG 0035 & 7.13 & -163.89 & -8.14 \\
MLGG 0254 & 0.46 & -113.16 & 8.54 \\
\hline
\end{tabular}




\section{Conclusion}

In Mn toxicity condition, the highest root dry weight was achieved by MLGG 0091. The high root dry weight in this genotype was also supported by the root length and number of roots. Decrease percentage of the root length in MLGG 0091 was classified as low if compared to other genotypes. In addition, MLGG 0091 was also capable to increase the length epicotyle that contribute to the increase in seedling dry weight. Therefore MLGG 0091 can be used as a source of Mn tolerant genes.

\section{References}

Abou M., Symeonidis L., Hatzistavrou E., \& Yupsanis T. (2002). Nucleolytic activities and appearance of a new DNase in relation to nickel and manganese accumulation in Alyssum murale. J. Plant Physiol., 159, 1087-1095. http://dx.doi.org/10.1078/0176-1617-00667

Adams F. (1981). Nutritional imbalances and consntraints to plant growth on acid soils. J. Plant Nutr., 4, 81-87. http://dx.doi.org/10.1080/01904168109362905

Foy C. D., Scott B. J., \& Fisher J. A. (1988). Genetics differences in plant tolerance to manganese toxicity. p. 293-307. In R. D. Graham et al. (Eds.), Manganese in soils and plants. Kluwer Acad. Publ. Dordrecht, Netherland.

Goss M. J., Carvalho M. J. G. P. R., \& Kirby E. A. (1991). Predicting toxic concentration in acid soils. p. 729-732. In R. J. Wright et al. (Eds.), Plant-soils interactions at low pH. Kluwer Acad. Publ. Dordrecht, Netherland.

Hajiboland R., Aliasgharpour M., Dashtbani F., Movafeghi A., \& Dadpour M. R. (2008). Localization and Study of Histochemical Effects of Excess Mn in Sunflower (Helianthus annuus L. cv. Azarghol) Plants. Journal of Sciences, Islamic Republic of Iran, 19, 305-315.

Heenan D. P., \& Carter O. G. (1976). Tolerance of soybean cultivars to manganese toxicity. Crops Sci., 16, 389-391. http://dx.doi.org/10.2135/cropsci1976.0011183X001600030018x

Horst W. J. (1988). The physiology of manganese toxicity. p. 175-188. In R. D. Graham et al. (Eds.), Manganese in soils and plants. Kluwer Acad. Publ. Dordrecht, Netherland.

Horst W. J., \& Marschner H. (1978). Effect of silicone on manganese tolerance on bean plant (Phaseolus vulgaris). Plant and Soil, 50, 287-303. http://dx.doi.org/10.1007/BF02107179

Hue N. V. (1988). A possible mechanism for manganese toxicity in Hawaii soils amended with a low-sewage sludge. J. Environ. Qual., 17, 473-479. http://dx.doi.org/10.2134/jeq1988.00472425001700030022x

Hue N. V., Fox R. L., \& McCall W. W. (1987). Aluminum, Ca, and Mn concentrations in macadamia seedlings as affected by soil acidity and liming. Commun. Soil Sci. Plant Anal., 18, 1253-1267. http://dx.doi.org/10.1080/00103628709367897

Izaguirre-Mayoral M. L., \& Sinclair T. R. (2005). Soybean genotypic difference in growth, nutrient accumulation and ultrastructure in response to manganese and iron supply in solution culture. Annals of Botany, 96, 149-158. http://dx.doi.org/10.1093/aob/mci160

Johansson J. (2005). Manganese solubility due to compaction in soils under corn and soybean. Institutionen för markvetenskap. Uppsala.

Junior J. L., Malavolta E., Nogueira Nd. L., Moraes M. F., Reis A. R., Rossi M. L., \& Cabral C. P. (2009). Changes in anatomy and root cell ultrastructure of soybean genotypes under manganese stress. R. Bras. Ci. Solo., 33, 395-403. http://dx.doi.org/10.1590/S0100-06832009000200017

Kassem, My. A., Meksem, K., Kang, C. H., Njiti, V., Kilo, V., Wood, A. J., \& Lightfoot, D. A. (2004). Loci underlying resistance to manganese toxicity mapped in a soybean recombinant inbred line population of "Essex" x "Forrest". Plant and Soil, 260, 197-204. http://dx.doi.org/10.1023/B:PLSO.0000030189.96115.21

Khabaz-Saberi H., Rengel Z., Wilson R., \& Setter T. L. (2009). Variation of tolerance to manganese toxicity in Australian hexaploid wheat. J. of Plant Nut. and Soil Sci., 173, 103-112. http://dx.doi.org/10.1002/jpln. 200900063

Marschner, H. (1995). Mineral nutrition of higher plants (2nd ed.). Academic Press. San Diego, CA.

Millaleo R., Reyes-Díaz M., Ivanov A. G., Mora M. L., \& Alberdi M. (2010). Manganese as essential and toxic element for plants: transport, accumulation and resistance mechanisms. J. Soil Sci. Plant Nutr., 10, $476-$ 494. http://dx.doi.org/10.4067/S0718-95162010000200008 
Reddy M. R, Ronaghi A., \& Bryant J. A. (1991). Differential responses of soybean genotypes to excess manganese in an acid soil. Plant and Soil, 134, 221-226. http://dx.doi.org/10.1007/BF00012039

Reis dos A. R., \& Junior J. L. (2011). Genotypic influence on the absorption, use and toxicity of manganese by soybean. Soybean - Molecular Aspects of Breeding. InTech. Retrieved from http://www.intechopen.com/ books/soybean-molecularaspects-of-breeding/genotypic-influence-on-the-absorption-use-and-toxicity-of-m anganese-by-soybean

Sparow L. A., \& Uren N. C. (1987). Oxidation and reduction of Mn in acidic soils: Effect of temperature and soil pH. Soil Biol. Biochem., 19, 143-148. http://dx.doi.org/10.1016/0038-0717(87)90073-3

Stone A. T., \& Morgan J. J. (1984). Reduction and distribution of manganese (III) and manganese (IV) oxides by organics: 2. Survey of the reactivity of organics. Environ. Sci. Technol., 18, 617-624. http://dx.doi.org/10. $1021 / \mathrm{es} 00124 \mathrm{a} 011$

\section{Copyrights}

Copyright for this article is retained by the author(s), with first publication rights granted to the journal.

This is an open-access article distributed under the terms and conditions of the Creative Commons Attribution license (http://creativecommons.org/licenses/by/3.0/). 